\title{
Developmental trajectories of nations based on equity, historic responsibility, and planetary boundaries
}

\author{
Soumyajit Bhar and Chirag Dhara \\ School of Interwoven Arts and Sciences, Krea University, Sri City 517646, India \\ *Soumyajit Bhar \\ Email: soumyajit.bhar@krea.edu.in (twitter handle: @BharSoumyajit) \\ Email ID of Chirag Dhara: chirag.dhara@krea.edu.in
}

Competing Interest Statement: The authors declare no competing interests.

Keywords: Human development, climate and ecological pressures, equity, historic responsibility, planetary boundaries.

This PDF file includes:

Main Text

Figures 1 to 3

Tables 1 


\begin{abstract}
A major challenge for humanity today is to articulate a developmental vision that can achieve a reasonable quality of life for the global population of over 7 billion without breaching sustainability limits. The Human Development Index (HDI) (UNDP 2010), which externalizes the planetary pressures of economic growth, promotes misguided development models since countries scoring highest on HDI have transgressed multiple planetary boundaries (O'Neill et al. 2018). The question that arises is whether templates of development exist among the fraternity of nations that may be sustainably scaled to the global population. We study this by constructing a new conceptual framework foregrounding the principles of equity, historic responsibility, and planetary boundaries. We propose a new environmentally-driven measure of human development - called the eHDI - that internalizes the climate and ecological pressures of economic growth. Analysis of the developmental trajectories of countries over the past three decades based on the eHDI reveals profound insights. We identify Panama, Costa Rica, Albania, Sri Lanka, and Georgia as the top examplar models that can provide reasonably high levels of human development to the entire global population with low environmental pressures. However, a conservative extrapolation of current trends indicates that only the Sri Lankan and Costa Rican trajectories may remain (largely) within planetary boundaries by 2050. Our results, therefore, foreground these two countries as the ones that merit the most focus in sustainability policy studies.
\end{abstract}

\title{
Significance Statement
}

An issue central to sustainability studies is identifying aspirational, scalable human development models compatible with sustaining climate and ecological integrity. The Human Development Index (HDI) is a misplaced metric since countries with very high HDIs also exact high environmental costs. We propose modifying the HDI by adjusting for environmental pressures, underpinned by the principles of equity, historic responsibility, and planetary boundaries. Belying its simplicity, this framework provides profound insights into the past and future developmental trajectories of nations. We identify the trajectories of Costa Rica, Albania, Sri Lanka, and Georgia as the best available models of sustainable development. However, the extrapolation of current trends indicates that only the Sri Lankan and Costa Rican models may remain sustainable by 2050. 


\section{Main Text}

\section{Introduction}

The past few centuries have seen tremendous progress in human development with sustained growth in access to food, water, health, education, and material wealth (Global Sustainable Development Report 2019). Fundamental to these developments has been the discovery of fossil fuels whose high energy densities have enabled the transformation of the Earth's natural capital into material wealth at unprecedented rates (Steffen, Broadgate, et al. 2015).

However, the increasing environmental pressures of aggregate human activity are already causing planetary-wide climate and ecological destabilization (IPBES 2019; Masson-Delmotte et al. 2021), while inequities in access to material resources have led to large disparities around the world (Piketty 2013). Therefore, only a minority of the global population has benefitted from high levels of development, concentrated mainly in the Global North and in pockets of affluence in the Global South. This raises the profound issue central to sustainability studies: how can higher levels of development be achieved for the rest of the global population while maintaining climate and ecological integrity? One approach to this question is to examine the historical developmental trajectories of countries to identify which of these can be sustainably scaled to the global population.

A standard metric of progress is the Human Development Index (HDI). The HDI is closely linked to a host of indicators of progress such as improved life expectancy, years of schooling, and reduced child mortality (Roser, Ortiz-Ospina, and Ritchie 2013; Roser, Ritchie, and Dadonaite 2013; Roser and Ortiz-Ospina 2016). However, the limitations of the HDI in failing to factor in environmental pressures of economic growth have become evident in the face of the accelerating climate and ecological crises. The HDI alone, therefore, promotes misguided models of development, evidenced by the fact that countries scoring highest on HDI have transgressed multiple planetary boundaries, in per capita terms, making their trajectories impossible to scale to the global population (O'Neill et al. 2018).

Several recent studies have sought to advance measures of development that internalize environmental pressures (Togtokh and Gaffney 2010; Türe 2013; Bravo 2014; Hirai 2017; Biggeri and Mauro 2018). These measures have been valuable in advances towards developing environmentally aware measures of human development. However, a fundamental weakness of 


\section{ENVIRONMENTAL PRESSURES ADJUSTED HUMAN DEVELOPMENT INDEX}

most of these approaches has been failing to satisfactorily account for ecological pressures (Hickel 2020b).

A new metric termed "Planetary pressures adjusted HDI" (PHDI) has recently gained prominence from being employed in the 'Human Development Report 2020' released by the United Nations Development Programme (UNDP) (UNDP 2020). The PHDI uses the 'material footprint' - defined as the aggregate mass of construction minerals, metal ores, fossil fuels, and biomass - used in the economy as a measure of the ecological pressures of development (van der Voet, van Oers, and Nikolic 2004; Krausmann et al. 2009; Wiedmann et al. 2015). The material footprint is used by the PHDI to penalize countries for the ecological pressures of their development. While this is a progressive development in principle, the methodology to compute PHDI suffers from serious flaws, and the results so obtained stand essentially invalidated (see "Discussion").

A more promising proposal is the Sustainable Development Index (SDI) proposed in Hickel, 2020 (Hickel 2020b). The SDI is similar in its mathematical formulation to the HDI but differs in important aspects: 1. It places a sufficiency threshold on per capita income, 2. Measures environmental pressures against 'planetary boundaries' (Rockström et al. 2009a; 2009b; Steffen, Richardson, et al. 2015), and 3. foregrounds equity. This approach results in a significant reordering in the country rankings on the SDI relative to the HDI. While the SDI approach brings a more robust accounting for environmental pressures of growth, it is subject to certain limitations:

1. The sufficiency limit on per-capita income is justified based on empirical data but is subject to a degree of arbitrariness, 2 . It does not fully account for historical responsibility, and 3. It is unclear how sensitive the obtained results are to the specific mathematical cost functions chosen to penalize ecological overshoot. Moreover, it cannot be inferred from that analysis alone how the ecological pressures of the best-performing countries may scale in the future.

Here, we have formulated a new metric of development (henceforth called the eHDI for brevity; environmental pressures adjusted $\mathrm{HDI}$ ) which has commonalities with the metrics discussed above but seeks to place them within a comprehensive conceptual framework underpinned by the principles of equity and historic responsibility. Unlike the UNDP's PHDI, which is a relative measure of sustainability, the metric we propose is an objective measure of 'strong sustainability' assessed against planetary boundaries for climate and ecological pressures. We use this metric to assess the scalability of the developmental trajectories of different countries to the global population. In so doing, we identify the best available templates of human development after 
adjusting for environmental pressures. We extrapolate current trends in these pressures for nations worldwide to project how their trajectories may evolve in the coming decades.

We discuss these results below and interpret them in the context of recent work.

\section{Results}

Table 1 ranks select countries by eHDI for 2019, identifying Panama, Costa Rica, Albania, Sri Lanka, and Georgia as the top performers.

The top 10 countries on eHDI are medium-income countries with HDIs ranging between 0.74 to 0.82. Three of the top five countries have achieved HDIs greater than 0.8 , classified as "very high" by the UNDP. Conversely, all countries with HDIs greater than 0.9 - exclusively high-income nations - are ranked lower than 55 on eHDI (Supplementary Table S1), indicating the high environmental pressures associated with their living standards. The highest-ranked among western European countries is Portugal (rank = 43), and the lowest is Finland (rank =111). Parts of Eastern Europe and North Africa perform significantly better, with Albania, Georgia, Tunisia, Armenia, and Algeria ranked in the top 20 on eHDI. The worst performers among the highincome/high-HDI countries are Singapore, Australia, Canada, the USA, and the UAE, which rank near the bottom on eHDI because of their exceptionally high environmental pressures. Russia and China present interesting case studies, ranking in the top 50 on eHDI, with medium-high HDIs and relatively moderate environmental pressures. In contrast, India, with a medium HDI and low environmental pressures, ranks 64 on eHDI placing it between Ireland and Italy.

Table 1 Ranking of select countries by eHDI for 2019.

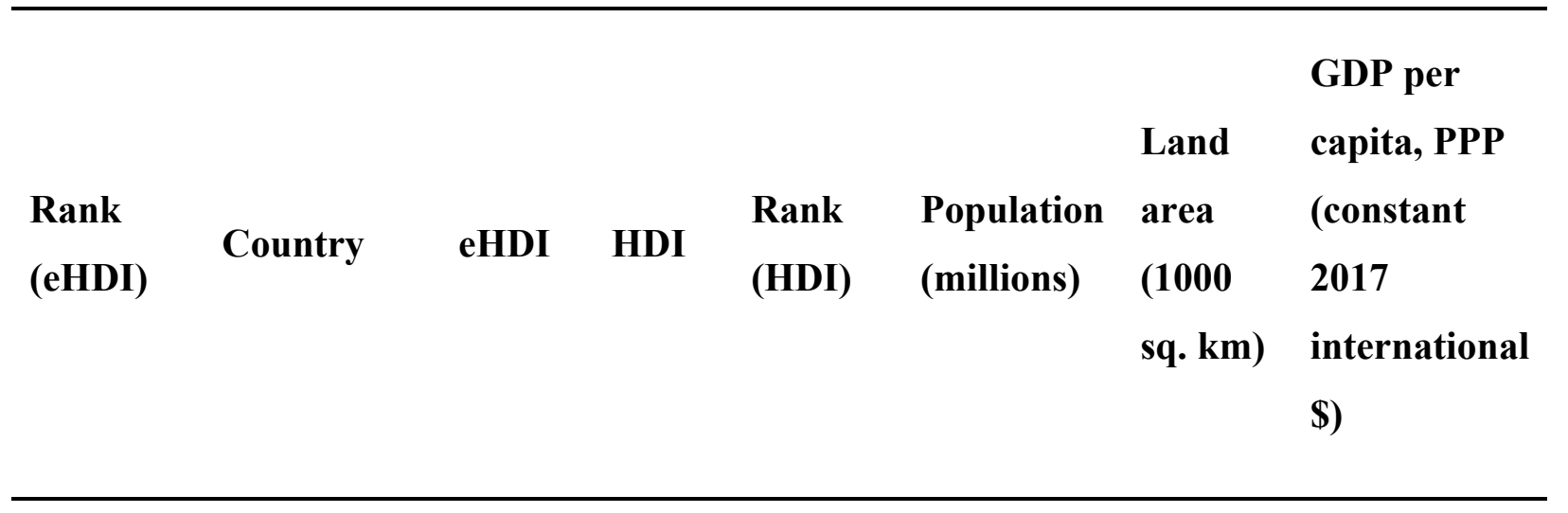

\section{Top 10 on eHDI}


ENVIRONMENTAL PRESSURES ADJUSTED HUMAN DEVELOPMENT INDEX

\begin{tabular}{|c|c|c|c|c|c|c|c|}
\hline 1 & Panama & 0.855 & 0.815 & 50 & 4.25 & 74 & 31,432 \\
\hline 2 & Costa Rica & 0.854 & 0.81 & 55 & 5.05 & 51 & 20,805 \\
\hline 3 & Albania & 0.837 & 0.795 & 62 & 2.88 & 27 & 13,671 \\
\hline 4 & Sri Lanka & 0.832 & 0.782 & 65 & 21.32 & 63 & 13,070 \\
\hline 5 & Georgia & 0.831 & 0.812 & 54 & 4 & 69 & 14,989 \\
\hline 6 & Peru & 0.824 & 0.777 & 70 & 32.51 & 1,280 & 12,854 \\
\hline 7 & $\begin{array}{l}\text { Dominican } \\
\text { Republic }\end{array}$ & 0.811 & 0.756 & 78 & 10.74 & 48 & 18,413 \\
\hline 8 & Colombia & 0.81 & 0.767 & 74 & 50.34 & 1,110 & 14,585 \\
\hline 9 & Cuba & 0.808 & 0.783 & 63 & 11.33 & 104 & 9,100 \\
\hline 10 & Fiji & 0.8 & 0.743 & 83 & 0.89 & 18 & 13,684 \\
\hline
\end{tabular}

\section{Selected countries}

\begin{tabular}{llllllll}
\hline 11 & Ecuador & 0.799 & 0.759 & 77 & 17.37 & 248 & 11,371 \\
\hline 12 & Tunisia & 0.798 & 0.74 & 84 & 11.69 & 155 & 10,756 \\
\hline
\end{tabular}


BHAR AND DHARA

\begin{tabular}{|c|c|c|c|c|c|c|c|}
\hline 14 & Armenia & 0.793 & 0.776 & 72 & 2.96 & 28 & 13,654 \\
\hline 22 & Mauritius & 0.78 & 0.804 & 59 & 1.27 & 2 & 22,870 \\
\hline 27 & Brazil & 0.771 & 0.765 & 75 & 211.05 & 8,358 & 14,764 \\
\hline 31 & Viet Nam & 0.769 & 0.704 & 103 & 96.46 & 310 & 8,041 \\
\hline 37 & Mexico & 0.758 & 0.779 & 67 & 127.58 & 1,944 & 19,701 \\
\hline 36 & $\begin{array}{l}\text { Russian } \\
\text { Federation }\end{array}$ & 0.758 & 0.824 & 46 & 145.87 & 16,377 & 27,211 \\
\hline 43 & Portugal & 0.745 & 0.864 & 34 & 10.23 & 92 & 34,880 \\
\hline 50 & China & 0.736 & 0.761 & 76 & 1433.78 & 9,388 & 16,092 \\
\hline 56 & Switzerland & 0.73 & 0.955 & 2 & 8.59 & 40 & 70,920 \\
\hline 59 & Gabon & 0.725 & 0.703 & 104 & 2.17 & 258 & 14,950 \\
\hline 61 & Ireland & 0.722 & 0.955 & 3 & 4.88 & 69 & 87,786 \\
\hline 64 & India & 0.72 & 0.645 & 115 & 1366.42 & 2,973 & 6,714 \\
\hline 66 & Bhutan & 0.715 & 0.654 & 113 & 0.76 & 38 & 11,832 \\
\hline
\end{tabular}


ENVIRONMENTAL PRESSURES ADJUSTED HUMAN DEVELOPMENT INDEX

$\begin{array}{llllllll}77 & \text { New } & 0.706 & 0.931 & 13 & 4.78 & 263 & 42,878\end{array}$

\begin{tabular}{|c|c|c|c|c|c|c|c|}
\hline 83 & Botswana & 0.703 & 0.735 & 88 & 2.3 & 567 & 17,777 \\
\hline 91 & Germany & 0.69 & 0.947 & 5 & 83.52 & 349 & 53,639 \\
\hline 93 & Japan & 0.689 & 0.919 & 19 & 126.86 & 365 & 41,380 \\
\hline 97 & Norway & 0.683 & 0.957 & 1 & 5.38 & 365 & 64,453 \\
\hline 105 & $\begin{array}{l}\text { United } \\
\text { Kingdom }\end{array}$ & 0.672 & 0.932 & 12 & 67.53 & 242 & 46,406 \\
\hline 129 & Singapore & 0.621 & 0.938 & 11 & 5.8 & 1 & 98,412 \\
\hline 136 & Canada & 0.615 & 0.929 & 15 & 37.41 & 9,094 & 49,007 \\
\hline 137 & Australia & 0.609 & 0.944 & 8 & 25.2 & 7,682 & 49,456 \\
\hline
\end{tabular}

United

$145 \quad$ States of $\quad \begin{array}{lllllll}0.601 & 0.926 & 16 & 329.06 & 9,147 & 62,631\end{array}$

America

$\begin{array}{llllllll}157 & \text { United Arab } & 0.54 & 0.89 & 28 & 9.77 & 201 & 12,809\end{array}$


Interesting patterns emerge across the world in examining the geographic variations of the eHDI (Fig. 1; top panel). South and Central America stand out as the best performing regions, with several countries ranking in the top 50. The worst performing regions are North America, Australia, the Middle East, and sub-Saharan Africa. Countries of sub-Saharan Africa, in general, perform poorly on eHDI on account of their poor performance on fundamental human developmental indicators. In contrast, the high performance on developmental indicators in the other regions is offset by the environmental pressures of their economy.

The spatial patterns of the difference between the HDI and eHDI ranks show wide variations around the world (Fig. 1; bottom panel). Most of the Global North and the Middle East countries exhibit a steep drop in rankings on eHDI relative to their HDI ranks, testifying to their high environmental pressures. The most significant improvement in rankings on eHDI occurs in South America, and East and South Asia, indicating that the human development achieved in these regions has entailed relatively low environmental pressures thus far. Some African nations also exhibit substantial gains, but this may be mainly because of the drop in rankings of more affluent nations.

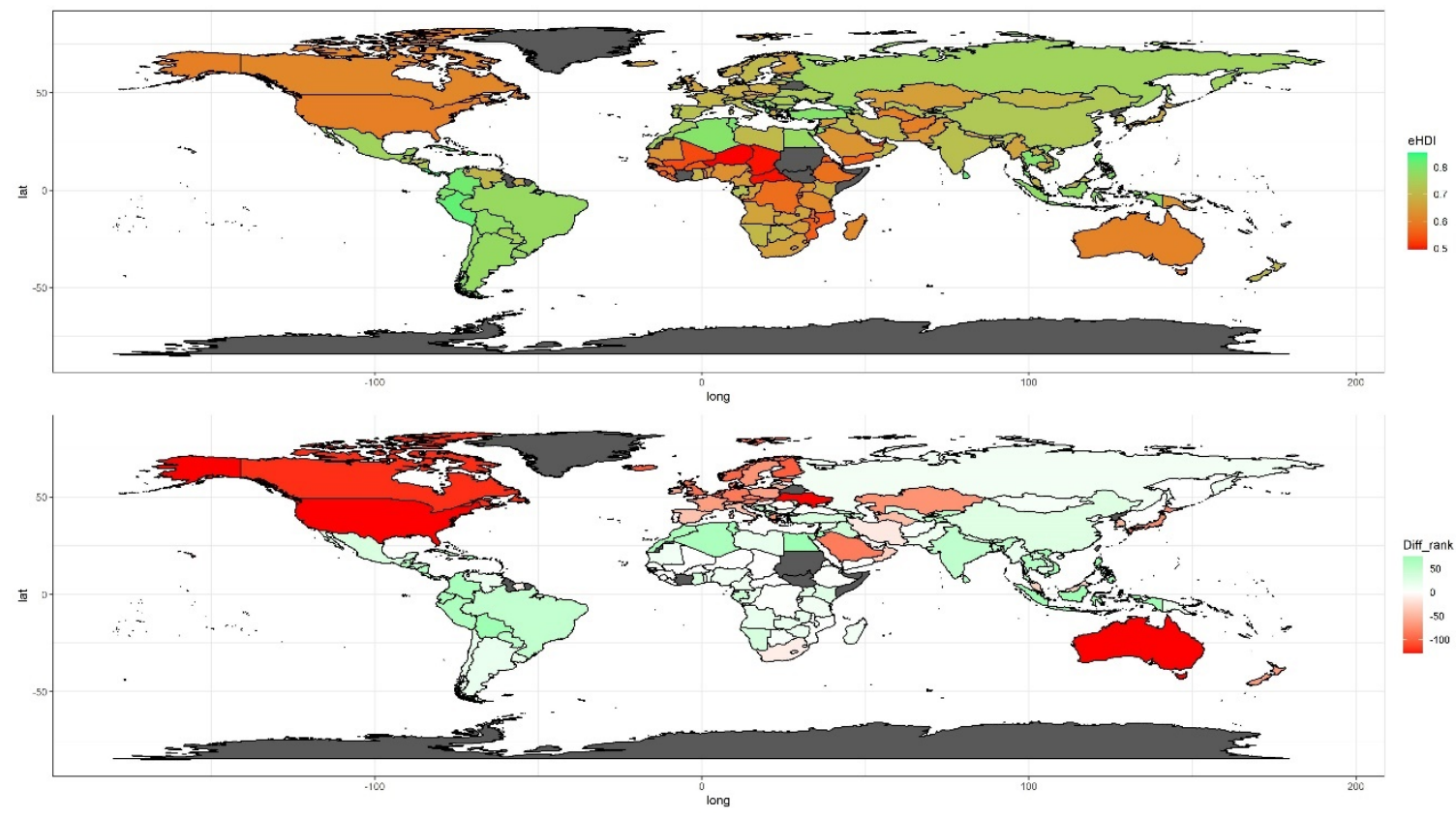

Figure 1: Spatial variations in eHDI (top panel) and the rank difference between HDI and eHDI (bottom panel; possitive values indicate better performance on eHDI than $H D I)$. 


\section{ENVIRONMENTAL PRESSURES ADJUSTED HUMAN DEVELOPMENT INDEX}

Analyzing the developmental indices for a single year, however, presents clear limitations. Environmental pressures may plausibly be rising even among those countries that rank high on eHDI in a given year; this cannot be inferred from the 2019 values alone. In that event, their trajectories may no longer remain sustainably scalable in the future. It is therefore important to identify the subset of nations with promising developmental trajectories that are likely to remain sustainable in the near future.

To this end, we examine the historical trajectories of HDI and eHDI for the last 30 years in Fig. 2 for select countries. Significant differences emerge in the patterns of relationship between eHDI and HDI. The trajectories of eHDI and HDI have remained nearly parallel over the last 30 years for Costa Rica, Sri Lanka, Peru, Cuba, and Ecuador, signaling that their human development remains sustainably scalable to the global population to the present day. In contrast, the eHDI and HDI trajectories are converging for Armenia, China (see also Supplementary Fig. S1), signaling that the environmental pressures of their development now exceed planetary boundaries at the global scale. The value of HDI when eHDI and HDI begin converging sheds light on the optimal level of scalable human development within planetary boundaries (see also Supplementary Fig. S4, S5, \& S6). Additional insights are obtained by looking into how the eHDI and HDI stack up against each other for G20 countries (Supplementary Fig. S2) that house about $60 \%$ of the world's population and account for $80 \%$ of the world's GDP. The eHDIs of Australia, the USA, UK, Canada, and UAE are found not just to be very low but declining over the past decade. This signifies that contrary to claims of 'absolute decoupling' (Bleischwitz 2010; OECD 2011), the environmental pressures of these countries continue to rise, as also reported in previous studies (Wiedmann et al. 2015; Hickel and Kallis 2019). The same patterns also hold for Japan, South Korea, France, and Germany, but the difference between eHDI and HDI is not quite as notable. The environmental pressures of emerging economies such as Argentina, Russia, Brazil, Mexico, China, and Turkey are considerably lower but have increased over the past decade. India and Indonesia are the only G20 nations whose developmental trajectory remains within planetary boundaries. This is likely because the HDIs values for these two countries are substantially lower than the rest, hovering in the 0.6 - 0.7 range, at which point empirical evidence suggests that environmental pressures do not generally exceed planetary boundaries (Bedir and Yilmaz 2016; Hickel 2020b).

These results demonstrate that the environmental impacts of the Global North and middleeastern nations continue to rise. This profoundly challenges the school of thought that environmental impacts can be decoupled from economic growth through technology alone (Fischer-Kowalski 2011; Hatfield-Dodds et al. 2015; Schandl et al. 2016; Scheel, Aguiñaga, and Bello 2020). In a recent study, Hubacek et al. confirm absolute decoupling of carbon emissions 
for a small group of countries (Hubacek et al. 2021); however, no evidence of absolute 'resource decoupling' has been found (Wiedmann et al. 2015; Wiedenhofer et al. 2020). Indeed, several studies have forcefully argued that decoupling resource use from economic growth is highly unlikely for conceptual and pragmatic reasons (Ward et al. 2016; Fletcher and Rammelt 2017; Hickel and Kallis 2019; Parrique et al. 2019; Dhara and Singh 2021). These observations are substantiated by the plots for the top $20 \mathrm{HDI}$ countries based on our method (Supplementary Fig. S3).

Interestingly, countries ranking in the top 10 on eHDI are exclusively medium-income countries with small land areas, low population sizes, and HDI $<0.85$ (in 2019). This is consistent with previous studies reporting that no country has achieved very high levels of human development, measured by HDI, without exceeding multiple planetary boundaries (O'Neill et al. 2018). It also substantiates Hickel 2020's empirical hypothesis that incomes above a threshold do not necessarily translate into higher human wellbeing (measured through the other two components of the HDI) but necessarily inflict high environmental costs (Hickel 2020b).

In the earlier sections, what we refer to as the "environmental costs/pressures" of a given country is an integrated metric indicating an average of its climate and ecological pressures. This selection was made for the mathematical expedience of easy comparison with the UNDP's PHDI but is not justifiable on physical grounds. The environmental pressures term in our formulation (elndex) is a composite of separate climate (clndex) and ecological (mlndex) indices. Analysis of 
these terms separately in Fig. 3 lends deeper insight into why the pressures-adjusted trajectories of nations diverge as they do.

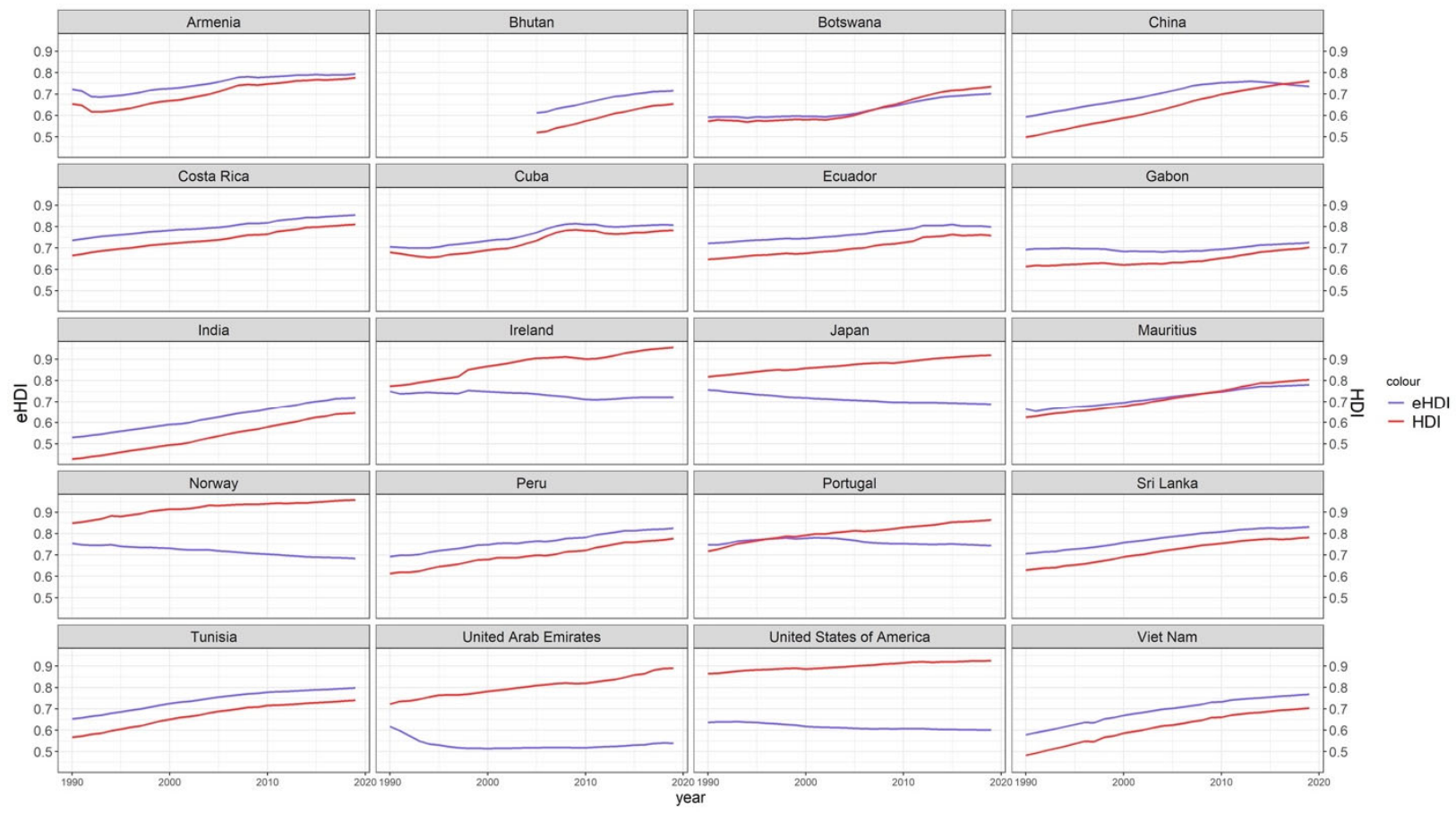

Figure 2: The trajectories of eHDI and HDI for select countries over 1990 - 2019. HDI for Bhutan is available only after 2005.

The solid lines in Fig. 3 signify the historical trends (1990 - 2019) in the clndex and mlndex for the same countries selected for Fig. 2. Lower values signify higher pressures. There is no clear pattern of the elndex being dominated by one of the component indices. The ecological pressures of countries such as Russia, South Africa, Germany, the UK, and the USA exceed the climate pressures. In contrast, countries like Spain, Korea, and Brazil indicate the opposite. It is important to note here that the climate pressures of all nations will continue to rise until they attain net-zero emissions. 


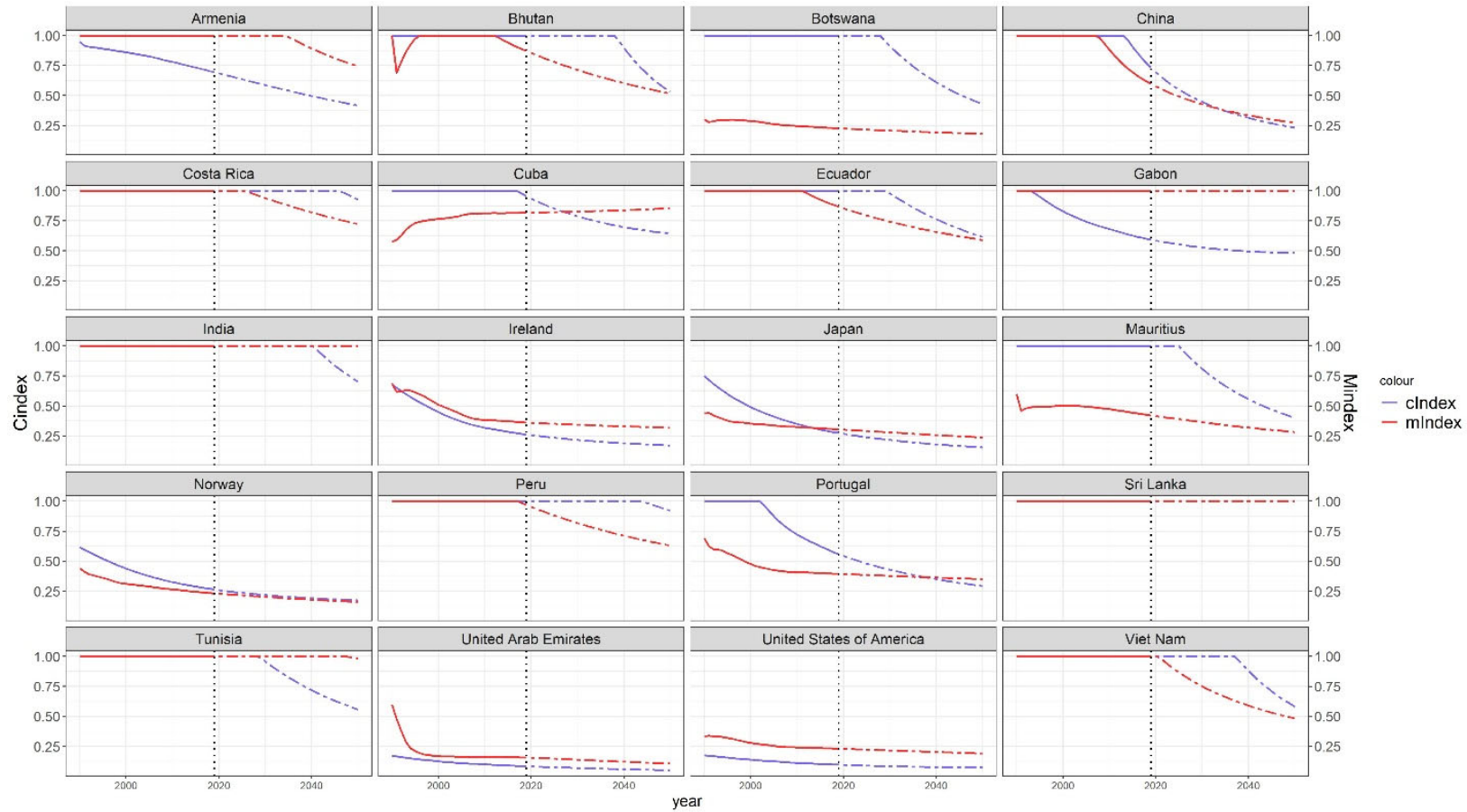

Figure 3: Historical (thick lines) and projected (dotted-dashed lines) trajectories for the same selection of countries as Fig. 2. The period 1990-2019 is plotted to the left of the vertical dotted line, and the right is the period from 2020-2050.

Having looked into the status of historical and present-day sustainability of national trajectories so far, finally, the question that arises is which are the most promising candidates for emulable development in the future. This question assumes significance since the planetary pressures of several countries in the top 20 on eHDI exhibit a growing trend. However, answering this question is complicated because the results of future projections are often sensitively contingent on assumptions about changes in technology (Hatfield-Dodds et al. 2015; Ward et al. 2016). Given the high stakes of continued unsustainability, we advocate for the "precautionary principle" instead of betting on assumptions about future technology. We, therefore, project the future changes in climate and ecological pressures (clndex and mlndex) for each country for the next three decades by linearly extrapolating their trends over the last decade. For this analysis, we use national and global population projections available from ourworldindata ${ }^{1}$. The dotted-dashed lines in Fig. 3 to the right of the vertical dotted lines represent projections until 2050 for the clndex and mlndex. Sri Lanka is a stand-out nation with environmental pressures remaining within planetary boundaries even out to 2050. The trajectories of Costa Rica and Peru also appear

\footnotetext{
${ }^{1}$ Source: Gapminder (v6), HYDE (v3.2), United Nations Population Division (2019).
} 


\section{ENVIRONMENTAL PRESSURES ADJUSTED HUMAN DEVELOPMENT INDEX}

promising but with greater environmental pressures than Sri Lanka. By the middle of the century, most other top eHDI countries significantly exceed the climate and ecological boundaries (Supplementary Fig. S7). Assuming that developing nations will continue to improve their HDIs, these projections substantiate the pattern that environmental costs are likely to rise sharply with higher "human development," seen narrowly in terms of the HDI. We also note that the environmental pressures of most developing economies of the G20, like Argentina, Brazil, Turkey, and South Africa, are also projected to increase substantially in coming decades (Supplementary Fig. S8). India and Indonesia are projected to present the lowest increase in environmental pressures, yet these are larger than Sri Lanka's.

\section{Discussion}

We have assessed the scalability of developmental trajectories of different countries to the global population in the context of planetary boundaries. Underpinning our framework are the principles of equity and historical responsibility. To our knowledge, this is the first work that analyses past trajectories and performs first-order future projections of the environmental footprints of nations. The countries we identify as the most promising trajectories do not find sufficient mention in the global conversation on 'sustainable development. Foregrounding these countries as the best available templates of equity and sustainability is the major contribution of this work. Our analysis points to Sri Lanka as the only known developmental model that may achieve a high level of human development within planetary boundaries over the next few decades. It, however, remains an open question whether the trajectories that we identify as most promising are amenable to global scaling in the real world. This may be the subject of future work.

Despite significant differences in methodology, our results bear a striking resemblance to those of Hickel 2020 (henceforth, H2020), which developed a metric called the Sustainable Development Index (SDI). The top 20 countries on the SDI metric are nearly identical to those on the eHDI. While both the SDI and eHDI use the carbon and material footprints, one of the main differences between $\mathrm{H} 2020$ and the current analysis is that the former places an empirical sufficiency constraint on income beyond which HDIs no longer benefit from higher incomes. Our analysis penalizes the exceedance of planetary boundaries instead of placing empirical sufficiency limits. That these two approaches lead to a nearly identical selection of top-performing countries may be interpreted as our formulation providing the conceptual validation for H2020's empirical income sufficiency constraint. In this sense, there are deep synergies between the two approaches worth exploring in greater detail. 
Our approach improves upon $\mathrm{H} 2020$ in certain vital aspects. Underpinning our formulation is a robust theoretical framework based on equity principles and an accounting for historical responsibility for climate change. This allows us to bypass empirical mathematical relationships and instead base our formulation on physical principles.

We also return to the discussion of the UNDP's recent PHDI metric, which we alluded to earlier (UNDP 2020). The PHDI also uses carbon and material footprints. However, results from the PHDI differ widely from ours, which we argue is the manifestation of a seriously flawed methodology by the UNDP. Firstly, the PHDI is a relative measure in which the concept of planetary boundaries is conspicuous by its absence. What this means in practice is that many countries with grossly unsustainable historical trajectories score high on PHDI merely because other countries have pursued even more historically unsustainable trajectories. Countries of the Global North benefit disproportionately from this method since their per capita carbon emissions were dwarfed by Qatar's 70 tonnes per capita in 1997. In addition, their material footprint was dwarfed by Guyana's 152.6 tonnes per capita in 2000 ("Planetary Pressures-Adjusted Human Development Index (PHDI) | Human Development Reports" 2020). By construction, this method precludes any significant reordering of the top ranks on PHDI compared to the HDI. In addition, the PHDI makes no effort to incorporate the principles of equity and historical responsibility. In short, if the purpose of the UNDP's development index is to identify aspirational models of sustainable development, then it not just fails at this task but may be argued to set a dangerous precedent by offering the illusion of an alternative.

We intentionally preserved key mathematical elements of the HDI and PHDI formulations to highlight that the radical country reorderings obtained from our approach are not an artifact of mathematical jugglery but the outcome of the principles that we foreground.

We now discuss the potential limitations of our framework. The material footprint is an aggregation of several different abiotic and biotic material resources, which does not distinguish between their different ecological impacts, relative abundances, rates of depletion, or significance to the economy. The merit of this approach is to detect cases of "problem shifting", where decoupling in a sector of the economy may occur because of a recoupling in another sector of the economy (Parrique et al. 2019). Conversely, the material footprint would fail to distinguish between the significance of, say, lithium on the one hand and plastics on the other to the economy as a whole. Therefore, while it is a good proxy for environmental pressures at global aggregate scales, it is insufficient for sectoral scale analysis. 


\section{ENVIRONMENTAL PRESSURES ADJUSTED HUMAN DEVELOPMENT INDEX}

Another point of contention may be of the quantitative choice of the planetary boundary. Although these were chosen in line with (O'Neill et al. 2018; Hickel 2020a), the question arises whether the country rankings would change significantly if these boundaries are chosen differently. To address this, we performed a sensitivity analysis by relaxing and tightening the planetary and ecological boundaries by $10 \%$, respectively. Few countries see any significant change in rankings (Supplementary Table S2).

A critique specific to this approach may be that population growth has been empirically observed to be inversely proportional to the level of human development, with the rates declining or reversing at high levels of HDI (Bongaarts 2009; Peterson 2017). Therefore, it may be argued that projecting the per-capita consumption of each country to the global population may unfairly penalize the Global North; the global population may have been smaller had human development globally been at par with the Global North (Bongaarts 2009). We studied this by constructing counterfactual worlds where the global population in 1850 evolves according to the annual rates of change observed in each of the 163 countries (see Supplementary Table S3 for the populations projected for 2019). The clndex, mlndex, and eHDls were calculated for this counterfactual global population (Supplementary Figs. S9 \& S10). Ireland tops the rankings in this counterfactual world (Supplementary Table S4), and many major European countries are among the top 20 (Germany, France, Italy, Portugal, Spain). Sri Lanka, Georgia, and Albania are the only three countries placed in the top 10 on actual and counterfactual eHDIs. The USA, Canada, UAE, and Australia remain among the worst performers on both.

In conclusion, the eHDI is a significant advance in efforts towards developing a simple metric to assess equitable, scalable human development within planetary boundaries. It sheds light on the optimal level of human development that can be achieved for all while maintaining ecological integrity. An important focus area for future work is to expand this framework to incorporate 'societal integrity', with indicators such as equitable access and individual freedoms (Biggeri and Mauro 2018; Brand et al. 2021).

\section{Materials and Methods}

Data. We use datasets for population, cumulative $\mathrm{CO} 2$ emissions, material footprint, and the HDI for 163 countries over the period 1990 - 2015. Population (https://ourworldindata.org/grapher/population) and cumulative CO2 emissions (https://ourworldindata.org/grapher/cumulative-co-emissions) datasets are from Ourworldindata, and material footprint data is from the Global materials flow database (https://www.resourcepanel.org/global-material-flows-database). The cumulative $\mathrm{CO} 2$ emissions 
dataset in ourworldindata is sourced from the Global Carbon Project: Global Carbon Project. (2020).

Methods. The $e H D I$ is defined as the HDI scaled by an environmental cost function that penalizes climate and ecological pressures exceeding planetary boundaries. We use each country's material footprint and cumulative carbon emissions as proxies for that country's ecological and climate pressures.

The total environmental cost function $(e C F)$ for the year $t$ is defined as,

$$
\operatorname{eCF}(t)=\frac{1}{2}(\operatorname{Cindex}(t)+\operatorname{Mindex}(t)),
$$

where the Cindex $(t)$ and $\operatorname{Mindex}(t)$ quantify the climate and ecological pressures in the year $t$. This form is chosen for consistency with the PHDI.

The detail of how Cindex and Mindex were calculated is not shared in this preprint version as the work is currently under review. Those details can be obtained upon an email request to the corresponding author.

\section{Calculating the eHDI.}

These two indices are used to calculate the environmental cost function $\operatorname{eCF}(t)$ and used to calculate the $e H D I(t)$ as,

$e H D I(t)=\sqrt[4]{H D I(t)^{3} * e C F(t)}$.

This form of the $e H D I$ makes it consistent with the usual definition of the HDI, a geometric mean over three standard dimensions related to human development (UNDP 2010). Therefore, the $e H D I$ is defined as the geometric mean over the same three dimensions and $e C F$ as the fourth to quantify environmental pressures.

\section{Acknowledgments}

We thank Shoibal Chakravarty and Aditi Deshpande for their valuable comments on the manuscript. 


\section{References}

Bedir, Serap, and Vildan Merve Yilmaz. 2016. "CO2 Emissions and Human Development in OECD Countries: Granger Causality Analysis with a Panel Data Approach." Eurasian Economic Review 6 (1): 97-110. https://doi.org/10.1007/s40822-015-0037-2.

Biggeri, Mario, and Vincenzo Mauro. 2018. "Towards a More 'Sustainable' Human Development Index: Integrating the Environment and Freedom." Ecological Indicators 91 (February): 220-31. https://doi.org/10.1016/j.ecolind.2018.03.045.

Bleischwitz, Raimund. 2010. "International Economics of Resource Productivity - Relevance, Measurement, Empirical Trends, Innovation, Resource Policies." International Economics and Economic Policy 7 (2): 227-44. https://doi.org/10.1007/s10368-010-0170-z.

Bongaarts, John. 2009. "Human Population Growth and the Demographic Transition." Philosophical Transactions of the Royal Society B: Biological Sciences 364 (1532): 2985-90. https://doi.org/10.1098/rstb.2009.0137.

Brand, Ulrich, Barbara Muraca, Éric Pineault, Marlyne Sahakian, Anke Schaffartzik, Andreas Novy, Christoph Streissler, et al. 2021. "From Planetary to Societal Boundaries: An Argument for Collectively Defined Self-Limitation." Sustainability: Science, Practice and Policy 17 (1): 265-92. https://doi.org/10.1080/15487733.2021.1940754.

Bravo, Giangiacomo. 2014. "The Human Sustainable Development Index: New Calculations and a First Critical Analysis." Ecological Indicators 37 (February): 145-50. https://doi.org/10.1016/j.ecolind.2013.10.020.

Desai, M. 1995. "Greening of the HDI?" In Accounting for Change, 21-36. London: The New Economics Foundation.

Dhara, Chirag, and Vandana Singh. 2021. "The Elephant in the Room: Why Transformative Education Must Address the Problem of Endless Exponential Economic Growth." In Curriculum and Learning for Climate Action: Toward an SDG 4.7 Roadmap for Systems Change [R. lyengar, C. Kwauk (Eds.)]. Brill. https://brill.com/view/book/9789004471818/BP000021.xml.

Fischer-Kowalski, Marina. 2011. Decoupling Natural Resource Use and Environmental Impacts from Economic Growth: A Report of the Working Group on Decoupling to the International Resource Panel. Paris: UNEP United Nations Environment Programme, International Resource Panel.

Fletcher, Robert, and Crelis Rammelt. 2017. "Decoupling: A Key Fantasy of the Post-2015 Sustainable Development Agenda." Globalizations 14 (3): 450-67. https://doi.org/10.1080/14747731.2016.1263077.

Global Sustainable Development Report. 2019. "Global Sustainable Development Report 2019: The Future Is Now - Science for Achieving Sustainable Development." New York: United Nations. https://sustainabledevelopment.un.org/content/documents/24797GSDR_report_2019.pdf.

Hatfield-Dodds, Steve, Heinz Schandl, Philip D. Adams, Timothy M. Baynes, Thomas S. Brinsmead, Brett A. Bryan, Francis H.S. Chiew, et al. 2015. "Australia Is 'free to Choose' Economic Growth and Falling Environmental Pressures." Nature 527 (7576): 49-53. https://doi.org/10.1038/nature16065.

Hickel, Jason. 2020a. "Quantifying National Responsibility for Climate Breakdown: An EqualityBased Attribution Approach for Carbon Dioxide Emissions in Excess of the Planetary Boundary." The Lancet Planetary Health 4 (9): e399-404. https://doi.org/10.1016/S25425196(20)30196-0.

2020b. "The Sustainable Development Index: Measuring the Ecological Efficiency of Human Development in the Anthropocene." Ecological Economics 167 (December): 106331. https://doi.org/10.1016/j.ecolecon.2019.05.011.

Hickel, Jason, and Giorgos Kallis. 2019. "Is Green Growth Possible?" New Political Economy 0 (0): 1-18. https://doi.org/10.1080/13563467.2019.1598964.

Hirai, Tadashi. 2017. The Creation of the Human Development Approach. Cham: Palgrave Macmillan. 
Hubacek, Klaus, Xiangjie Chen, Kuishuang Feng, Thomas Wiedmann, and Yuli Shan. 2021. "Evidence of Decoupling Consumption-Based CO2 Emissions from Economic Growth." Advances in Applied Energy, October, 100074. https://doi.org/10.1016/j.adapen.2021.100074.

IPBES. 2019. "Global Assessment Report on Biodiversity and Ecosystem Services of the Intergovernmental Science-Policy Platform on Biodiversity and Ecosystem Services." https://doi.org/10.5281/zenodo.5517154.

Krausmann, Fridolin, Simone Gingrich, Nina Eisenmenger, Karl-Heinz Erb, Helmut Haberl, and Marina Fischer-Kowalski. 2009. "Growth in Global Materials Use, GDP and Population during the 20th Century." Ecological Economics 68 (10): 2696-2705. https://doi.org/10.1016/j.ecolecon.2009.05.007.

Masson-Delmotte, Valérie, Panmao Zhai, Anna Pirani, Sarah L. Connors, C. Péan, Sophie Berger, Nada Caud, et al., eds. 2021. Climate Change 2021: The Physical Science Basis. Contribution of Working Group I to the Sixth Assessment Report of the Intergovernmental Panel on Climate Change. Cambridge University Press.

Neumayer, Eric. 2001. "The Human Development Index and Sustainability - a Constructive Proposal." Ecological Economics 39 (1): 101-14. https://doi.org/10.1016/S09218009(01)00201-4.

OECD. 2011. "Resource Productivity in the G8 and the OECD - A Report in the Framework of the Kobe 3R Action Plan - OECD." https://www.oecd.org/env/waste/resourceproductivityintheg8andtheoecd.htm.

O'Neill, Daniel W., Andrew L. Fanning, William F. Lamb, and Julia K. Steinberger. 2018. "A Good Life for All within Planetary Boundaries." Nature Sustainability 1 (2): 88-95. https://doi.org/10.1038/s41893-018-0021-4.

Parrique, T., J. Barth, F. Briens, C. Kerschner, A. Kraus-Polk, A. Kuokkanen, and J.H. Spangenberg. 2019. "Decoupling Debunked - Evidence and Arguments against Green Growth as a Sole Strategy for Sustainability." European Environmental Bureau. https://eeb.org/library/decoupling-debunked/.

Peterson, E. Wesley F. 2017. "The Role of Population in Economic Growth." SAGE Open 7 (4): 2158244017736094. https://doi.org/10.1177/2158244017736094.

Piketty, Thomas. 2013. "Capital in the Twenty-First Century." 2013. https://www.hup.harvard.edu/catalog.php?isbn=9780674979857.

"Planetary Pressures-Adjusted Human Development Index (PHDI) | Human Development Reports." 2020. 2020. http://www.hdr.undp.org/en/content/planetarypressures\%E2\%80\%93adjusted-human-development-index-phdi.

Rockström, Johan, Will Steffen, Kevin Noone, Åsa Persson, F. Stuart Chapin, Eric F. Lambin, Timothy M. Lenton, et al. 2009a. "A Safe Operating Environment for Humanity." Nature 461|24 (September): 472-75. https://doi.org/10.5751/ES-03180-140232.

Rockström, Johan, Will Steffen, Kevin Noone, Åsa Persson, F. Stuart Chapin, Eric Lambin, Timothy M. Lenton, et al. 2009b. "Planetary Boundaries: Exploring the Safe Operating Space for Humanity." Ecology and Society 14 (2). https://doi.org/10.1038/461472a.

Sagar, Ambuj D, and Adil Najam. 1998. "The Human Development Index: A Critical Review." Ecological Economics 25 (3): 249-64. https://doi.org/10.1016/S0921-8009(97)00168-7.

Schandl, Heinz, Steve Hatfield-Dodds, Thomas Wiedmann, Arne Geschke, Yiyong Cai, James West, David Newth, Tim Baynes, Manfred Lenzen, and Anne Owen. 2016. "Decoupling Global Environmental Pressure and Economic Growth: Scenarios for Energy Use, Materials Use and Carbon Emissions." Journal of Cleaner Production, Absolute Reductions in Material Throughput, Energy Use and Emissions, 132 (September): 45-56. https://doi.org/10.1016/j.jclepro.2015.06.100.

Scheel, Carlos, Eduardo Aguiñaga, and Bernardo Bello. 2020. "Decoupling Economic Development from the Consumption of Finite Resources Using Circular Economy. A Model for Developing Countries." Sustainability (Switzerland) 12 (4): 1-21. https://doi.org/10.3390/su12041291. 
Steffen, Will, Wendy Broadgate, Lisa Deutsch, Owen Gaffney, and Cornelia Ludwig. 2015. "The Trajectory of the Anthropocene: The Great Acceleration." Anthropocene Review 2 (1): 81-98. https://doi.org/10.1177/2053019614564785.

Steffen, Will, Katherine Richardson, Johan Rockström, Sarah E. Cornell, Ingo Fetzer, Elena M. Bennett, Reinette Biggs, et al. 2015. "Planetary Boundaries: Guiding Human Development on a Changing Planet." Science 347 (6223): 1259855. https://doi.org/10.1126/science.1259855.

Togtokh, Chuluun, and Owen Gaffney. 2010. "2010 Human Sustainable Development Index." https://ourworld.unu.edu/en/the-2010-human-sustainable-development-index.

Türe, Cengiz. 2013. "A Methodology to Analyse the Relations of Ecological Footprint Corresponding with Human Development Index: Eco-Sustainable Human Development Index." International Journal of Sustainable Development \& World Ecology 20 (1): 9-19. https://doi.org/10.1080/13504509.2012.751562.

UNDP. 2010. "Human Development Report 2010: The Real Wealth of Nations - Pathways to Human Development." New York. http://hdr.undp.org/en/content/human-developmentreport-2010.

— 2020. "The next Frontier: Human Development and the Anthropocene." New York, NY: United Nations Development Programme.

Voet, Ester van der, Lauran van Oers, and Igor Nikolic. 2004. "Dematerialization: Not Just a Matter of Weight." Journal of Industrial Ecology 8 (4): 121-37. https://doi.org/10.1162/1088198043630432.

Ward, James D., Paul C. Sutton, Adrian D. Werner, Robert Costanza, Steve H. Mohr, and Craig T. Simmons. 2016. "Is Decoupling GDP Growth from Environmental Impact Possible?" PLoS ONE 11 (10): 1-14. https://doi.org/10.1371/journal.pone.0164733.

Wiedenhofer, Dominik, Doris Virág, Gerald Kalt, Barbara Plank, Jan Streeck, Melanie Pichler, Andreas Mayer, et al. 2020. "A Systematic Review of the Evidence on Decoupling of GDP, Resource Use and GHG Emissions, Part I: Bibliometric and Conceptual Mapping" 15 (6): 063002. https://doi.org/10.1088/1748-9326/ab8429.

Wiedmann, Thomas O., Heinz Schandl, Manfred Lenzen, Daniel Moran, Sangwon Suh, James West, and Keiichiro Kanemoto. 2015. "The Material Footprint of Nations." Proceedings of the National Academy of Sciences of the United States of America 112 (20): 6271-76. https://doi.org/10.1073/pnas.1220362110. 